УДК 330.01:338.47.656

ГРНТИ 06.52.13, 06.52.45

\title{
Организационно-экономический механизм повышения экономической безопасности России в условиях построения цифровой экономики
}

\author{
3.К. Зоидов \\ e-mail: zafar2608@mail.ru
}

\begin{abstract}
Аннотация
В статье рассматриваются современные механизмы и направления в решении задач обеспечения экономической безопасности страны на основе расширения доли российских разработок в отношении внедряемых цифровых технологий. С целью развития конкурентного потенциала обосновывается необходимость содействия субъектам цифровых производств с учетом трендов «цифровой революции» в повышении их привлекательности для инвестиций и иных мероприятий в этой сфере. Содействие реализации концепции Индустрии 4.0 раскрывается с позиции реализации в рамках списка импортных комплектующих и технологий, подлежащих первоочередному замещению в сфере высокотехнологичных производств.

Статья подготовлена в рамках государственного задания ИПР РАН, тема НИР «Моделирование социально-экономической динамики и структуры факторов экономического роста ЕАЭС и других стран в контексте модернизации».
\end{abstract}

Ключевые слова: организационно-экономический механизм, экономическая безопасность, информационно-коммуникационнье технологии, цифровая экономика

DOI: https://doi.org/10.33051/2500-2325-2019-1-50-57

\section{Введение}

Актуальность и сложность решения проблем обеспечения экономической безопасности в условиях необходимости решения задачи перехода к новому - более высокому - уровню цифровизации экономики России с учетом мировых трендов «цифровой революции» требует разработки эффективных подходов к практическому решению глобальных и локальных проблем в этой области [1-11]. В связи с этим, исследование процессов обеспечения экономической безопасности с опорой на цифровые технологии преимущественно российской разработки с возможностью снижения ущерба от действующих и вероятных будущих санкций со стороны ряда западных стран становятся все более актуальным как с научной, так и с практической точек зрения [5].

1. Восстановление на новом технологическом уровне ключевых стратегических компетенций в области производства электронного оборудования

С целью развития конкурентного потенциала необходимо оказывать содействие субъектам цифровых производств с учетом трендов «цифровой революции» в повышении их привлекательности для инвестиций и иных мероприятий в этой сфере. Содействие реализации концепции Индустрии 4.0 должно реализовываться в рамках списка импортных комплектующих и технологий, подлежащих первоочередному замещению в сфере высокотехнологичных производств. Это предполагается обеспечить за счет реализации комплекса информационных, организационных, нормативно-законодательных и иных мер, стимулирующих импортозамещение при заказах и поставках.

Существует задача восстановления на новом технологическом уровне ключевых стратегических компетенций в области производства электронного оборудования и модернизации, участвующих в таком производстве, российских компаний и их дочерних и зависимых обществ. Сегодня наиболее эффективные механизмы для обеспечения экономической безопасности путем расширения доли российских разработок в отношении внедряемых цифровых технологий - это организационные структуры, реализующие направления развития электронных закупочных систем (ЭТП) с встроенными сервисами замещения иностранных комплектующих. 
Для восстановления на новом технологическом уровне ключевых стратегических компетенций в области производства электронного оборудования необходимо налаживание процессов управления разнопрофильными системами и партнерами в бесшовной цепочке создания добавленной стоимости в российском сегменте мировой экономики. Формирование новых приборостроительных производств предполагает достижение мирового уровня цифровых составляющих российских технологий различных профилей, опирающихся на интеллектуальные сервисы опорной цифровой инфраструктуры и интеграции стационарных и мобильных источников данных как единого распределенного массива информации.

Причем предметная область проекта формирования новых приборостроительных производств может быть различной - от разработки национальной системы, способной обеспечить баланс комплектующих отечественного и зарубежного производства для цифровой инфраструктуры до организации действий в другой стране, на другом континенте [10]. Внедрение интеллектуальных систем с учетом приоритетов обеспечения экономической безопасности требует наращивание инвестиций в отечественное производство аппаратно-программных комплектующих для цифровой инфраструктуры [11]. Формирующиеся приборостроительные производства сами должны использовать цифровые сервисы как базу для нового этапа цифровизации промышленности [2]. Этот этап характеризуется восстановлением на новом технологическом уровне ключевых стратегических компетенций в области производства электронного оборудования на основе использования цифровых платформ IoT (Internet of Things) и обработки в режиме он-лайн сверхбольших объемов данных, получаемых от стационарных и мобильных объектов.

Отличительной особенностью современного периода развития организационноцифрового управления полным циклом создания телекоммуникационного оборудования, приборов и программ при формировании инфраструктуры цифровой экономики является усложнение процедур за счет усложнения решения задач ситуационно-когнитивного синтеза интерактивных многофункциональных сетей из физических и коммуникационных компонент. Сейчас формирование в России интерактивных многофункциональных сетей из физических и коммуникационных компонент реализуется практически полностью в рамках идеологии крупных зарубежных компаний. В то же время обеспечение экономической безопасности требует цифровой «упаковки» кооперационных форматов интеллектуальной трансформации производства с опорой преимущественно на российские инновации, с первоочередной заменой импортных комплектующих телекоммуникационных узлов (маршрутизаторов и пр.). Функциональная и структурная сложность современных организационных структур обусловливает особые требования к надежности обеспечения сетевых управленческих функций с внедрением отечественных разработок при цифровизации различных видов предметной деятельности, в первую очередь на общероссийском уровне.

\section{2. Проблемы государственного регулирования цифровых проектов}

Сегодня в рамках обеспечения экономической безопасности необходимо повышение наблюдаемости на всех уровнях управления. Зарубежный опыт свидетельствует о возможности формирования виртуальных системно-структурных информационных центров как основы повышения управляемости различных секторов цифровой экономики. Последующая интеграция виртуальных системно-структурных информационных центров в рамках приоритетов обеспечения экономической безопасности (при условии постепенного устранения доминирования иностранных аппаратных и программных составляющих) позволит в конечном итоге сформировать условия для фазового перехода «слепой» экономики, базирующейся на статической отчетности к «прозрачной» экономике с наращиванием информационно-вычислительных преимуществ для мониторинга, анализа, прогнозирования и регулирования как элементов процесса обеспечения экономической безопасности.

С появлением новых направлений цифровой деятельности возникает потребность обеспечения эффективных механизмов защиты интеллектуальных прав российских товаропроизводителей, что, например, в отношениях с китайскими компаниями несет ряд серьезных проблем практического характера. Прежде всего, существенно затрудняется наращивание российского 
экспорта инновационно-цифровых технологических решений. Если раньше эта проблема была малоактуальной вследствие незначительности такого экспорта, то расширение мер и ускорение темпов инновационно - цифрового преобразования актуализирует данную проблему на будущий период. Внедрение преимущественно российских технологических решений предполагает развитие нормативно-правовой базы, охраняющей права российских товаропроизводителей с усложнением доступа иностранных конкурентов к возможности воровства нужных им российских инноваций.

Серьезной проблемой для экономической безопасности является отсутствие системного подхода в России при создании интеллектуального (умного) производства, умных сетей и услуг, умных зданий и инфраструктуры, умного транспорта и пр., так как эти проекты не увязываются между собой, а просто встраиваются в неоцифрованную инфраструктуру [4]. Вообще проблема системного регулирования новых цифровых проектов с позиций обеспечения экономической безопасности крайне важна, так как позволяет в будущем сэкономить огромные финансовые средства за счет устранения дублирующих секторов цифровой инфраструктуры при создании различных элементов цифровой экономики [6;8].

Вышеперечисленные мероприятия отвечают общей направленности осуществляемых в государстве реформ, отображают специфику цифровых производств с учетом трендов «цифровой революции» и важность государственного регулирования цифровых проектов. Особо сложной проблемой для обеспечения экономической безопасности является развитие сетевых форматов в системе евразийской научно-производственной кооперации, так как наши партнеры по Евразийскому экономическому союзу идут по пути «наименьшего сопротивления», не создавая собственные приборостроительные производства, а прибегая к скрытому импорту из Китая. Заинтересованности во внедрении российских разработок в других государствах-членах ЕАЭС нет.

Изложенные проблемы регулирования цифровых проектов при цифровой трансформации экономики нашей страны и партнеров по Евразийскому экономическому союзу предполагают выработку общих детализированных стратегий реализации концепции Индустрии 4.0 в решении общих задач цифровизации ЕАЭС.

Принятие общих детализированных стратегий в решении общих задач цифровизации ЕАЭС должно служить основой формирования государственной политики каждого государства-члена ЕАЭС, совершенствования нормативно-правовой базы цифровых производств с учетом трендов «цифровой революции», разработки государственных и международных целевых кластерных программ в части развития цифровых производств. Особенно важно внедрение в рамках ЕАЭС модели совместного использования государственными ведомствами и коммерческими структурами (облачных) центров предоставления вычислительных мощностей и информационных сервисов, при решении общих задач цифровизации ЕАЭС. Здесь также возникает необходимость доработки общих механизмов информационной безопасности ЕАЭС, которая тесно взаимосвязана с экономической безопасностью.

\section{3. Проблемы импортозамещения для российских промышленных предприятий}

Главным препятствием для импортозамещения является отсутствие российских аналогов оборудования и сырья (даже при наличии платежеспособного спроса). На рис.1 приведены помехи импортозамещению для российских промышленных предприятий.

В условиях отсутствия необходимых российских аналогов возможность обеспечить баланс комплектующих отечественного и зарубежного производства для цифровой инфраструктуры крайне проблематична. Для решения этой проблемы автором предлагается расширение возможного рынка и перечня поставщиков с учетом не только других государств-членов ЕАЭС, но и ряда других государств, зависимость от которых в сфере ИКТ создает меньшие угрозы экономической безопасности чем, например, от стран, входящих в НАТО или от некоторых азиатских стран, имеющих территориальные претензии к России. Среди расширенного круга поставщиков могут быть такие страны, как Австрия, Вьетнам, Финляндия, Малайзия и пр. 


\section{Отсутствие отечественных аналогов оборудования и сырья любого качества \\ Низкое качество отечественного оборудования и сырья \\ Недостаточная поддержка властями выпуска отечественного оборудования и сырья}

Недостаточные объемы выпуска отечественного оборудования и сырья

Завышенные цены на отечественное оборудование и сырье

Bсе еще приемлемые цены на импортное оборудование и сырье

Недостаточные административные запреты (санкции) на импорт оборудования и сырья

Оттягивание самим предприятием перехода на отечественное оборудование и сырье

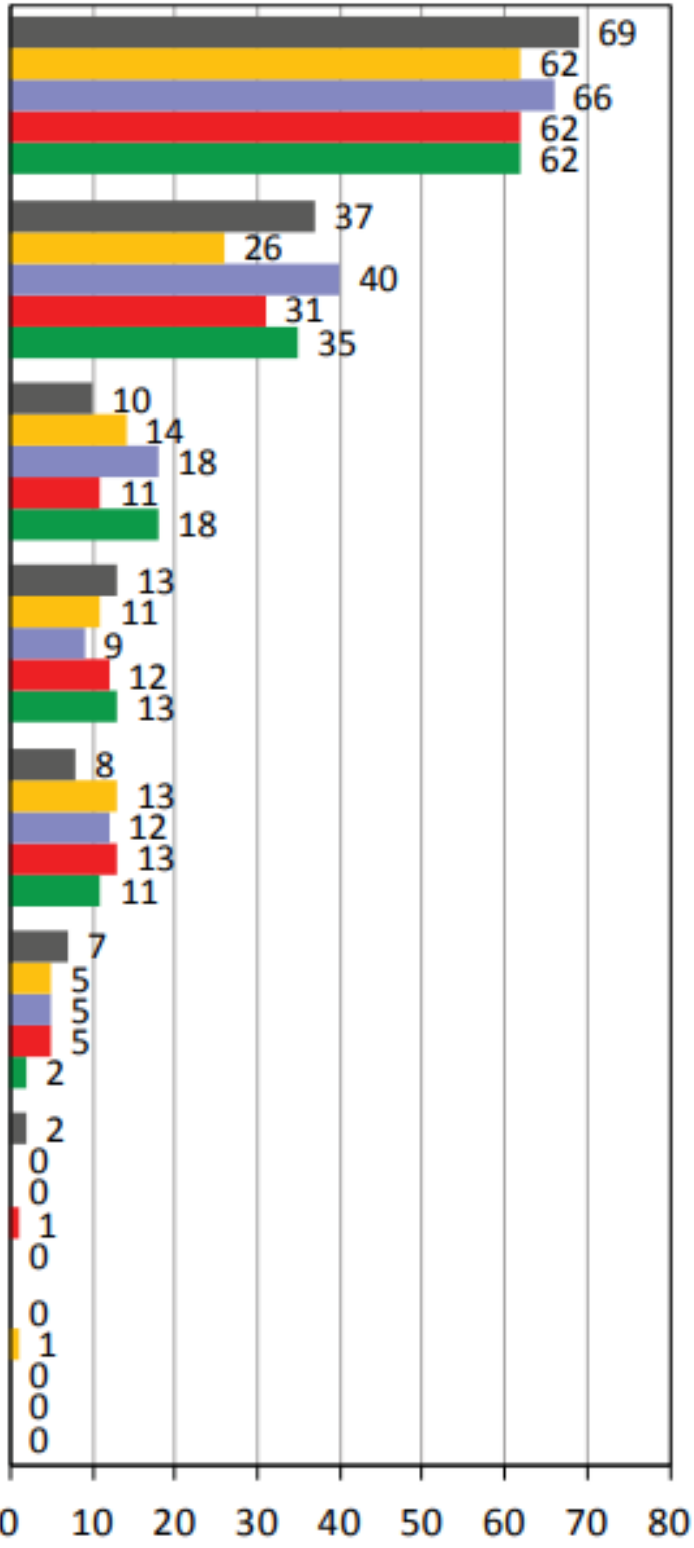

— 2017 июль 2016 октябрь 2016 март 2015 август $\square 2015$ январь

Рис.1. Помехи импортозамещению для российских промышленных предприятий в 2015-2017 гг., \% [7].

При этом возникает еще одна проблема, имеющая отношение к обеспечению экономической безопасности. Это проблема того, сможет ли наша страна сформировать полноценный комплекс гражданского приборостроения с учетом ресурсных и прочих ограничений [1]. Необходимо учесть, что бывший СССР и его приборостроительная отрасль и научный комплекс, формирующие собственные заделы в сфере информационных технологий были рассчитаны на поставки не только потребителям самого СССР (условно 270 млн. чел.), но и социалистическим странам, странам социалистической ориентации, неприсоединившимся странам и пр. с общим контуром потребителей около 1,2 млрд. чел. (Китай сюда не входит, а Индия входит только частично). В условиях такого объема поставок (квази - рынков) достигалась окупаемость и научной и производственной части этой отрасли СССР. 


\section{4. Системные риски в обеспечении экономической безопасности проекта восстановления в России приборостроительной отрасли}

Выделим ряд системных рисков в обеспечении экономической безопасности (табл.1).

\section{Системные риски обеспечения экономической безопасности проекта восстановления в России приборостроительной отрасли}

\begin{tabular}{|c|c|}
\hline Риски (вопросы) & Меры по их минимизации \\
\hline $\begin{array}{l}\text { Хватит ли у Российской Федерации финан- } \\
\text { совых ресурсов для создания полноценной } \\
\text { конкурентоспособной (например, по отно- } \\
\text { шению к Германии) приборостроительной } \\
\text { отрасли? }\end{array}$ & $\begin{array}{l}\text { К государственным финансовым ресурсам на } \\
\text { эти цели можно было бы добавить инвестиции } \\
\text { тех стран, которые хотели бы принять участи } \\
\text { в поставках оборудования при создании новых } \\
\text { производств в России }\end{array}$ \\
\hline $\begin{array}{l}\text { Найдутся ли в России необходимые инже- } \\
\text { нерные, научные, квалифицированные рабо- } \\
\text { чие и пр. кадры для работы на новых произ- } \\
\text { водствах приборостроительной отрасли с } \\
\text { учетом качественной и количественной де- } \\
\text { градации высококвалифицированного тру- } \\
\text { дового потенциала страны за последние 10- } \\
15 \text { лет? }\end{array}$ & $\begin{array}{l}\text { С учетом того, что приборостроительные про- } \\
\text { изводства сейчас максимально автоматизиро- } \\
\text { ванные (роботизированные), то проблема по- } \\
\text { иска кадров не является неразрешимой. Часть } \\
\text { кадров можно было бы привлечь на Украине. }\end{array}$ \\
\hline $\begin{array}{l}\text { Каковы территориальные зоны, а также объ- } \\
\text { емы и структура платежеспособного гаран- } \\
\text { тированного спроса на продукцию этих но- } \\
\text { вых российских производств? }\end{array}$ & $\begin{array}{l}\text { Территориальная зона поставок с платежеспо- } \\
\text { собным спросом - это ЕАЭС, а также часть } \\
\text { развивающихся стран, прежде всего, Азии. }\end{array}$ \\
\hline $\begin{array}{l}\text { Каково влияние глобальных и локальных } \\
\text { кризисных явлений на развитие этого рос- } \\
\text { сийского проекта? }\end{array}$ & $\begin{array}{l}\text { Кризисные явления не отменяют мировой } \\
\text { тренд «цифровой революции», некоторое огра- } \\
\text { ничение динамики деловой активности вслед- } \\
\text { ствие кризисных явлений требует фокусировки } \\
\text { первоочередных мер стимулирования цифр-- } \\
\text { вых преобразований. }\end{array}$ \\
\hline $\begin{array}{l}\text { Насколько эффективно зарубежные эконо- } \\
\text { мические и иные санкции, применяемые к } \\
\text { России странами Запада, смогут помешать } \\
\text { или замедлить реализацию этого проекта? }\end{array}$ & $\begin{array}{l}\text { Санкции могут затруднить техническое пере- } \\
\text { вооружение российской приборной промыш- } \\
\text { ленности, но остановить его не смогут. }\end{array}$ \\
\hline $\begin{array}{l}\text { Как скажутся меры по принудительному } \\
\text { ограничению импорта комплектующих в } \\
\text { сфере ИКТ на отношения России со страна- } \\
\text { ми, откуда эти поставки осуществляются } \\
\text { сейчас (Китай, Германия, США, Великобри- } \\
\text { тания и пр.)? }\end{array}$ & $\begin{array}{l}\text { Практически все страны применяют меры за- } \\
\text { щиты внутреннего рынка, поэтому даже при } \\
\text { недовольстве основных стран-импортеров в } \\
\text { Россию, серьезного охлаждения отношений не } \\
\text { будет. }\end{array}$ \\
\hline $\begin{array}{l}\text { Насколько полноценно российский суще- } \\
\text { ствующий и будущий научно-технический } \\
\text { задел сможет перекрыть ключевые техноло- } \\
\text { гии и патенты, принадлежащие американ- } \\
\text { ским ТНК, которые контролируют основной } \\
\text { объем интеллектуальной собственности в } \\
\text { сфере ИКТ? }\end{array}$ & $\begin{array}{l}\text { Полностью российские разработки не смогут } \\
\text { заменить ключевые технологии, принадлежа- } \\
\text { щие американским ТНК. Поэтому необходимо } \\
\text { сбалансированное постепенное вытеснение за- } \\
\text { рубежных технологий исходя из возможности } \\
\text { их замены. }\end{array}$ \\
\hline $\begin{array}{l}\text { С кем России стоит выстраивать междуна- } \\
\text { родную научно-техническую кооперацию в } \\
\text { этой сфере (страны, корпорации, рынки)? }\end{array}$ & $\begin{array}{l}\text { России необходимо выстраивать кооперацию с } \\
\text { традиционными партнерами - странами ЕАЭС, } \\
\text { а также кооперацию с теми странами, чьи тех- } \\
\text { нологии сложно заместить российскими разра- } \\
\text { ботками. }\end{array}$ \\
\hline $\begin{array}{l}\text { Сможет ли Россия догнать в рамках этого } \\
\text { проекта в ближайшем будущем далеко ото- } \\
\text { рвавшиеся от нее по ИКТ страны и ТНК? }\end{array}$ & $\begin{array}{l}\text { Россия сможет в ближайший период догнать } \\
\text { другие страны по ряду цифровых позиций, по } \\
\text { другим позициям это можно будет сделать } \\
\text { позднее. }\end{array}$ \\
\hline
\end{tabular}




\section{Заключение}

Представляется целесообразным активизировать процессы создания и использования опорной цифровой инфраструктуры с учетом оптимизации замещения имеющихся иностранных поставщиков с возможностями адаптации производства к быстро меняющимся условиям внешней и внутрироссийской конкурентной среды. Необходимо отметить, что существует критическая зависимость процессов политического суверенитета Российской Федерации от научно-технического и производственного суверенитета в сфере цифровых технологий. На первый план обеспечения экономической безопасности страны выходит эффективность стратегического управления на цифровой основе.

\section{Литература}

1. Агеев А.И., Логинов Е.Л. Формирование организационных и информационных механизмов управления построением в России цифровой экономики //Экономические стратегии. - 2018. - Т. 20. - № 3 (153). - С. 56-67.

2. Григорьев В.В., Деркач А.К. Построение инфраструктуры цифровой экономики: концентрация ключевых факторов конкурентоспособности. Материалы международной научнопрактической конференции «Выход из системной кризисной цикличности: проблемы и пути устойчивого экономического развития». - М.: ИПР РАН, 2018. - С. 37-39.

3. Иванов В.В., Малинецкий Г.Г. Цифровая экономика: мифы, реальность, перспектива. М.: ИПМ РАН, 2017. 64 с.

4. Козырев А.Н. Цифровая экономика и цифровизация в исторической ретроспективе [Электронный pecypc]. URL: https://medium.com/@anatolykozyrev_82073 (Дата обращения: 06.02.2019).

5. Логинов Е.Л., Шкута А.А. Цифровая суперсистема как инструмент управления мировой экономикой. - М.: Финансовый университет при Правительстве Российской Федерации, 2019. - 209 c.

6. Макаров В.Л., Бахтизин А.Р., Бурилина М.А. Перспективы цифровизации современного общества //Экономика и управление. - 2017. - № 11 (145). - С. 4-7.

7. Мониторинг экономической ситуации в России тенденции и вызовы социальноэкономического развития. - 2018. - № 2(63). [Электронный ресурc]. URL: https://www.iep.ru /files/RePEc/gai/monreo/monreo-2018-2-870.pdf (Дата обращения: 06.02.2019).

8. Развитие цифровой экономики в России как ключевой фактор экономического роста и повышения качества жизни населения: монография /Нижний Новгород. Издательство «Профессиональная наука», 2018. -131с.

9. Цветков В.А., Шутьков А.А., Дудин М.Н., Лясников Н.В. Цифровая экономика и цифровые технологии как вектор стратегического развития национального агропромышленного сектора //Вестник Московского университета. Серия 6: Экономика. - 2018. - № 1. - С. 45-64.

10. Цветков В.А., Зиядуллаев Н.С., Зоидов К.Х., Янкаускас К.С. Проблемы и перспективы развития цифровой экономики в России //Стратегические тренды трансформации социально-экономических систем в рамках цифровой экономики. Материалы международной научнопрактической конференции: Под редакцией В.А. Цветкова, К.Х. Зоидова. - М.: ИПР РАН, 2018. С. 207-215.

11. Яшин С.Н., Кулагова И.А., Малова С.А., Суханов Д.А. Формирование стратегии промышленной безопасности предприятий в условиях цифровой экономики //Экономика и предпринимательство. - 2018. - № 4 (93). - С. 1236-1241.

\section{Об авторе}

Зоидов Зафар Кобилджснович, научный сотрудник, Институт проблем рынка РАН, Москва.

\section{Для цитирования}

Зоидов 3.К. Организационно-экономический механизм повышения экономической безопасности России в условиях построения цифровой экономики //Проблемы рыночной экономики. - 2019. - № 1. - C. 50-57.

DOI: https://doi.org/10.33051/2500-2325-2019-1-50-57 


\title{
Organizational and economic mechanism to improve the economic security of Russia in the conditions of building digital economy
}

\author{
Zafar K. Zoidov \\ e-mail: zafar2608@mail.ru
}

\begin{abstract}
The article discusses modern mechanisms and directions in solving the tasks of ensuring the economic security of the country based on the expansion of the share of Russian developments in relation to the digital technologies being introduced. In order to develop a competitive potential, it is recognized that it is necessary to assist the subjects of digital production taking into account the trends of the "digital revolution" in increasing their attractiveness for investments and other activities in this area. The promotion of the implementation of the concept of Industry 4.0 is justified from the point of view of implementation within the list of imported components and technologies that are subject to priority replacement in the field of high-tech industries.
\end{abstract}

The article was prepared in the framework of the state task of the MEI RAS, the theme of research "Modeling of socio-economic dynamics and structure of economic growth factors of the EAEU and other countries in the context of modernization".

Keywords: organizational and economic mechanisms, economic security, information and communication technologies, digital economy

\section{References}

1. Ageev A.I., Loginov E.L. Formation of organizational and information management mechanisms for building a digital economy in Russia // Economic strategies. - 2018. - Vol. 20. - № 3 (153). P. 56-67 (In Russian).

2. Grigoriev V.V., Derkach A.K. Building the infrastructure of the digital economy: concentration of key factors of competitiveness //Proceedings of the international scientific and practical conference «Exit from the systemic crisis cycle: problems and ways of sustainable economic development». M.: MEI RAS, 2018. - P. 37-39 (In Russian).

3. Ivanov V.V., Malinetsky G.G. Digital economy: myths, reality, perspective. Moscow, IPM RAS, 2017. - 64 p. (In Russian).

4. Kozyrev A.N. The digital economy and the digitization in historical perspective [Electronic resource]. URL: https://medium.com/@anatolykozyrev_82073 (Access date: 06.02.2019, In Russian).

5. Loginov E.L., Shkuta A.A. Digital super system as a tool of world economy management. Moscow: Financial University under the Government of the Russian Federation, 2019. - 209 p. (In Russian).

6. Makarov V.L., Bakhtizin A.R., Burylin M. A. Prospects for the digitalization of modern society // Economy and management. - 2017. - № 11 (145). - P. 4-7 (In Russian).

7. Monitoring of the economic situation in Russia trends and challenges of socio-economic development. - 2018. - № 2 (63). [Electronic resource.]. URL: https://www.iep.ru/files/RePEc /gai/monreo /monreo-2018-2-870 ahhh.pdf (Access date: 06.02.2019, In Russian).

8. Development of the digital economy in Russia as a key factor of economic growth and improving the quality of life of the population: monograph /Nizhny Novgorod. Publishing house "Professional science", 2018. - 131 c. (In Russian).

9. Tsvetkov V.A., Shutkov A.A., Dudin M.N., Lyasnikov N.V. In. Digital economy and digital technologies as a vector of strategic development of the national agro-industrial sector //Bulletin Moscow state University. Series 6: Economics. - 2018. - № 1. - P. 45-64 (In Russian).

10. Tsvetkov V.A., Ziyadullaev N.S., Zoidov K.H., Yankauskas K.S. Problems and prospects of development of digital economy in Russia //Strategic trends of transformation of social and economic systems within the digital economy /Proceedings of the international scientific and practical conference. Edited by V.A. Tsvetkov, K.H. Zoidov. - M.: MEI RAS, 2018. - P. 207-215 (In Russian).

11. Yashin S.N., Kulagova I.A., Malova S.A., Sukhanov D.A. Formation of industrial safety strategy of enterprises in the digital economy //Economics and entrepreneurship. - 2018. - № 4 (93). P. 1236-1241 (In Russian). 
About author
Zafar K. Zoidov, Researcher, Market Economy Institute of RAS, Moscow.

For citation

Zoidov Z.K. Organizational and economic mechanism of increase of economic security of Russia in the conditions of construction of digital economy //Market economy problems. - 2019. - № 1 . - C. 50-57 (In Russian).

DOI: https://doi.org/10.33051/2500-2325-2019-1-50-57 